\title{
Analysis of Adherence to Antihypertensive Drug Treatment in an Argentinean Cohort
}

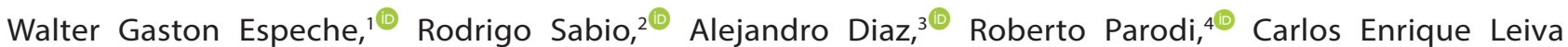 \\ Sisnieguez, ${ }^{5 \oplus}$ Roberto Antonio Flores, ${ }^{6 \oplus}$ Silvia Poppe, ${ }^{7}$ Javier Altube, ${ }^{2}$ Diego Grimaldi, ${ }^{2}$ Martin Rogelio Salazar ${ }^{5}$ \\ Interzonal General Hospital of Acutes Jose de San Martin, 'Buenos Aires - Argentina \\ Hospital Calafate, ${ }^{2}$ Santa Cruz - Argentina \\ CONICET Tandil, ${ }^{3}$ Buenos Aires - Argentina \\ Universidad Nacional de Rosario, ${ }^{4}$ Rosario - Argentina \\ Hospital Interzonal General de Agudos General San Martin, La Plata - Argentina \\ Hospital de Santiago del Estero, ${ }^{6}$ Santiago del Estero - Argentina \\ Hospital General de Agudos Juan A Fernandez,' Buenos Aires - Argentina
}

\section{Abstract}

Background: Adherence to antihypertensive medication is a major challenge in the management of hypertension, and non-adherence is an important barrier to effective management of hypertension.

Objectives: To determine the adherence rate to hypertensive drug treatment and the factors that influence nonadherence in a cohort of the Argentinean population.

Methods: A multicenter cross-sectional study was conducted in eight cities of Argentina. Consecutive hypertensive patients seen in general practice offices, receiving pharmacological treatment for at least six months were included. Blood pressure measurements were performed by physicians during the patient visit. The level of adherence was assessed using the Morisky questionnaire, and patients were divided into non-adherent and adherent. Continuous variables were compared using independent t-test. Categorical variables were compared using the $\chi^{2}$ test. To identify the variables independently associated with non-adherence, a forward stepwise binary regression logistic model was performed, and the results expressed as odds ratio (OR) with 95\% of confidence interval. All tests were two-tailed, and p-values $<0.05$ were considered statistically significant.

Results: A total of 852 individuals (52\% women, $62 \pm 13$ years) were included. The main reason for lack of adherence was forgetfulness of medication intake and errors in the time of intake ( $40 \%$ in both). Individuals with more cardiovascular risk factors (smoking, diabetes, dyslipidemia and previous cardiovascular events) had lower adherence to antihypertensive treatment, and considerably younger ( five years younger).

Conclusions: Adherence rate to antihypertensive drug treatment in our study group was higher than the one reported in previous studies, and the main reason for non-adherence was forgetfulness of medication intake. (Int J Cardiovasc Sci. 2020; 33(3):272-277)

Keywords: Hypertension/epidemiology; Risk Factors; Antihypertensive Agents; Cross-Sectional Study.

\section{Introduction}

Hypertension contributes to the global burden of cardiovascular disease and premature morbidity and mortality. ${ }^{1}$ The ability of pharmacological treatment of hypertension to reduce the risk of cardiovascular events and decrease morbidity and mortality is well established. ${ }^{2,3}$ Adherence to antihypertensive medication is a major challenge that clinicians often face in the management of hypertension. ${ }^{4}$ Moreover, non-adherence is the main obstacle to controlling hypertension in the community and a significant barrier to an effective management. ${ }^{5-7}$ Good adherence is therefore crucial to improve hypertension control rates and prevent complications such as stroke, coronary artery disease, aneurysms and heart failure..$^{8,9}$ 
Medication adherence is defined by the World Health Organization (WHO) as "the degree to which a person's behavior corresponds with the agreed recommendations from a health care provider." 10 The WHO estimates the prevalence of non-adherence to antihypertensive medication to be $30-50 \%$, depending on differences in drug-class, type of prevention and methods used to measure adherence. ${ }^{6,7,11}$ In Argentina, a study based on a non-population sample showed a rate of adherence of $26 \%{ }^{12}$ Remarkably, non-adherence was associated with higher cardiovascular risk..$^{13}$

Factors that influence adherence could be classified into five dimensions: 1 . patient-related factors (inadequate beliefs or skills), 2. socioeconomic-related factors (poor health literacy or low social support), 3. conditionrelated factors (presence of comorbidities), 4. therapyrelated factors (complex drug regimen) and 5 . health system/health-care team-related factors (inadequate communication with health-care provider). ${ }^{2}$

There are direct and indirect methods to assess adherence. While direct methods have the advantage of having greater accuracy, the cost, availability, and accessibility of these methods make their use unlikely in current practice. Conversely, indirect methods, such as the Morisky-Green test, are easy to use in daily medical practice (Table 3). ${ }^{14}$ Thus, this test could be used to evaluate adherence in real-world settings.

The aim of this study was to determine the prevalence of adherence in hypertensive patients treated by physicians in several cities in Argentina.

\section{Methods}

A multicenter cross-sectional study was conducted in eight cities of Argentina (Tandil, La Plata, El Calafate, Santiago del Estero, San Miguel de Tucumán, Rosario, Misiones and Buenos Aires) between March and August 2018 using a prospectively designed protocol. Each city was represented by a single centre. These cities are the capitals or the most important cities of six provinces (Buenos Aires, Santiago del Estero, Santa Fe, Santa Cruz, Tucuman and Misiones), in the North, South and Central regions of the country.

The study was conducted on consecutive hypertensive patients seen in the general practice office who had been under pharmacological treatment for at least six months.

Blood pressure (BP) measurements were performed by the physician in a single visit (regardless of the purpose of the visit), using an OMRON HEM $705 \mathrm{CP}$ device (OMRON HEALTHCARE Co., Kyoto, Japan). Two measures were taken, with a one-minute interval between measurements, and the mean of the measures was defined as office blood pressure. Body weight was determined with subjects wearing light clothes and no shoes. Height was measured without shoes using a metallic tape, and body mass index (BMI) was calculated. In addition, history of dyslipidemia, diabetes, cardiovascular diseases, and smoking was recorded.

The level of adherence was assessed using the Morisky questionnaire. ${ }^{14} \mathrm{~A}$ non-adherent patient was defined as a patient who answered positively to any one of the questions. Controlled hypertensive patients were defined as those individuals whose BP was $<140-90 \mathrm{mmHg}$. The type and number of antihypertensive drugs and the use of fixed-dose combinations were recorded. The patients willing to participate signed an informed consent form.

Individuals were divided into controlled and uncontrolled hypertension using the traditional definition ${ }^{4}$ and in "non-adherent" and "adherent" according to the Morisky test.

\section{Statistical analysis}

The study sample had a normal distribution determined by Test Shapiro Wilk. Baseline continuous variables (age, BMI, systolic BP, and diastolic BP) were expressed as mean \pm standard deviation (SD) and were compared using an independent t-test. Categorical variables (sex, current smokers, adherence, diabetes, dyslipidemia, hypertension control, and previous cardiovascular event) were expressed as percentages and compared using the $\chi^{2}$ test.

To identify the variables independently associated with non-adherence, a forward stepwise binary regression logistic model was performed and the results expressed as odds ratio (OR) with $95 \%$ of confidence interval (95\% CI).

All tests were two-tailed, and $\mathrm{P}$ values $<0.05$ were considered statistically significant. All statistical analyses were performed using SPSS 18.0.

\section{Results}

A total of 862 individuals aged $61 \pm 14$ years of age, 53\% women, from the eight cities (nearly 100 individuals per center) were included. Most patients $(79,1 \%)$ had health insurance and similar socioeconomic 
characteristics. All individuals completed high school. Ten patients were excluded due to lack of consent or blood pressure measurements.

Clinical characteristics of the remaining 852 patients are summarized in Table 1 . There were no differences in age, systolic BP, number of drugs used, BMI, previous cardiovascular events, smoking and control of hypertension between men and women. Global adherence to treatment was also not different between men and women, $61.3 \%$ and $63.1 \%$, respectively $(\mathrm{p}=0.444)$.

Table 2 shows that individuals who had controlled hypertension were more adherent to treatment $(69.3 \%$ vs. $53.3 \%$, p < 0.001). Also, they used more fixed-doses combinations of antihypertensive drugs $(p<0.001)$ and had lower BMI $(\mathrm{p}<0.001)$.

Inhibitors of the renin-angiotensin system (angiotensin receptor antagonists and angiotensin-converting enzyme inhibitors) were the most frequently used antihypertensives (46.8\%), followed by beta-blockers, calcium channel blockers and diuretics $(6.9 \%, 2.4 \%$, and $1.0 \%$ respectively). Diuretics were the most commonly used drugs as the second drug $(22.1 \%)$, and $13.5 \%$ of the patients used three or more antihypertensive drugs.

The most frequent reasons for lack of adherence were carelessness in the time of intake and forgetfulness of the medication intake. Remarkably, only a minority was not adherent due to adverse drug effects (Table 3 ).

As shown in Table 4, the non-adherent group was younger, had higher BP values, lower number of never- smokers, and higher frequency of previous cardiovascular events. Although there were no differences in BMI between adherent and non-adherent subjects, more obese

Table 1 - Characteristics of the sample by sex

\begin{tabular}{lccc}
\hline & $\begin{array}{c}\text { Women } \\
\mathbf{n}=444\end{array}$ & $\begin{array}{c}\text { Men } \\
\mathbf{n}=408\end{array}$ & p-value \\
\hline Age (years) & $62 \pm 13$ & $61 \pm 12$ & 0.346 \\
SBP (mmHg) & $138 \pm 18$ & $139 \pm 18$ & 0.458 \\
DBP (mmHg) & $82 \pm 11$ & $84 \pm 12$ & 0.002 \\
BMI (Kg/m ${ }^{2}$ ) & $29.7 \pm 6.5$ & $28.8 \pm 5.0$ & 0.149 \\
$\begin{array}{l}\text { Controlled hypertension } \\
\text { (\%) }\end{array}$ & 43.0 & 46.1 & 0.369 \\
$\begin{array}{l}\text { Hypercholesterolemia (\%) } \\
\text { Diabetes mellitus (\%) }\end{array}$ & 35.1 & 44.1 & 0.001 \\
$\begin{array}{l}\text { Smoking (\%) } \\
\text { Previous cardiovascular } \\
\text { event* (\%) }\end{array}$ & 21.8 & 29.2 & 0.026 \\
$\begin{array}{l}\text { Number of } \\
\text { antihypertensive drugs }\end{array}$ & 12.8 & 13.2 & 0.553 \\
$\begin{array}{l}\text { Fixed-dose drug } \\
\text { combinations(\%) }\end{array}$ & $1.6 \pm 0.8$ & $1.6 \pm 0.8$ & 0.174 \\
$\begin{array}{l}\text { Adherence (\%) } \\
\text { *acute myocardial infarction, stroke; SBP: systolic blood pressure; }\end{array}$ & & & \\
DBP: diastolic blood pressure. & & & \\
\hline
\end{tabular}

Table 2 - Characteristics of patients divided into controlled or uncontrolled hypertension

\begin{tabular}{lccc} 
& $\begin{array}{c}\text { Controlled hypertension } \\
\mathbf{n}=379\end{array}$ & $\begin{array}{c}\text { Uncontrolled hypertension } \\
\mathbf{n}=473\end{array}$ & p-value \\
& $62 \pm 15$ & $60 \pm 13$ & 0.043 \\
\hline Age (years) & $28.1 \pm 5.5$ & $31.0 \pm 6.4$ & 0.001 \\
BMI $\left(\mathrm{Kg} / \mathrm{m}^{2}\right)$ & 37.2 & 42.2 & 0.137 \\
Hypercholesterolemia (\%) & 22.2 & 29.3 & 0.018 \\
Diabetes mellitus(\%) & 11.4 & 15.0 & 0.228 \\
Smoking (\%) & 5.3 & 9.5 & 0.018 \\
Previous cardiovascular event ${ }^{*}(\%)$ & $1.5 \pm 0.8$ & 0.002 \\
Number of antihypertensive drugs & $1.7 \pm 0.8$ & 9.8 & 0.027 \\
Fixed-dose drug combinations(\%) & 14.8 & 53.3 & $<0.001$ \\
Adherence (\%) & 69.3 & & \\
\hline BMI: body mass index. & & & \\
\hline
\end{tabular}


patients $\left(\mathrm{BMI}>35 \mathrm{~kg} / \mathrm{m}^{2}\right)$ were less adherent than the rest of the sample. The use of fixed-dose combination antihypertensives was more frequent in adherent than non-adherent patients $(\mathrm{p}<0.001)$.

\begin{tabular}{l}
$\begin{array}{l}\text { Table } 3 \text { - Reasons for lack of adherence and percentage } \\
\text { of positive responses in the Morisky-Green-Levine test }\end{array}$ \\
$\begin{array}{l}\text { Questions } \\
\text { Positive } \\
\text { answers (\%) }\end{array}$ \\
$\begin{array}{l}\text { 1. Do you ever forget to take medications for } \\
\text { your hypertension? }\end{array}$ \\
$\begin{array}{l}\text { 2. Are you careless with the time you should } \\
\text { take the medication? } \\
\text { 3. When you are well, do you stop taking the } \\
\text { medication? } \\
\text { 4. If you ever feel bad, do you stop taking it? }\end{array}$ \\
\hline $\begin{array}{l}\text { 1-2. Execution. 3-4. Short persistence. } \\
\end{array}$
\end{tabular}

Table 4 - Characteristics of patients by adherence or not to pharmacological treatment

\begin{tabular}{lccc}
\hline & $\begin{array}{c}\text { Adherence } \\
\mathbf{n}=530\end{array}$ & $\begin{array}{c}\text { Non- } \\
\text { adherence } \\
\mathbf{n}=322\end{array}$ & p-value \\
& $63 \pm 13$ & $57 \pm 15$ & $<0.001$ \\
\hline Age (years) & $136 \pm 17$ & $142 \pm 19$ & $<0.001$ \\
SBP (mmHg) & $80 \pm 11$ & $85 \pm 12$ & $<0.001$ \\
$\begin{array}{l}\text { DBP (mmHg) } \\
\text { BMI (Kg/m })\end{array}$ & $29.0 \pm 5.5$ & $29.7 \pm 6.8$ & 0.094 \\
$\begin{array}{l}\text { Hypercholesterolemia } \\
\text { (\%) }\end{array}$ & 41.1 & 36.6 & 0.194 \\
$\begin{array}{l}\text { Diabetes mellitus(\%) } \\
\text { Never-smoking (\%) }\end{array}$ & 23.4 & 28.5 & 0.092 \\
$\begin{array}{l}\text { Previous } \\
\text { cardiovascular event } \\
\text { (\%) }\end{array}$ & 83.0 & 76.7 & 0.024 \\
$\begin{array}{l}\text { Number of } \\
\text { antihypertensive } \\
\text { drugs }\end{array}$ & $1.7 \pm 0.8$ & $1.5 \pm 0.8$ & 0.056 \\
$\begin{array}{l}\text { Fixed-dose drug } \\
\text { combination (\%) }\end{array}$ & & & \\
\hline $\begin{array}{l}\text { SBP: systolic blood pressure; DBP: diastolic blood pressure; BMI: body } \\
\text { mass index }\end{array}$ & & & \\
\hline & & & \\
\hline
\end{tabular}

In the logistic regression analysis, previous cardiovascular event was independently associated with lack of adherence (OR $=3.0195 \%$ CI 1.53-5.91). Conversely, fixed-dose drug combinations $(\mathrm{OR}=$ $0.2295 \% \mathrm{CI} 0.12-0.40)$ and older age ( $\mathrm{OR}=0.9795 \% \mathrm{CI}$ 0.96-0.0.98) were factors associated with higher adherence.

\section{Discussion}

In our study the prevalence of individuals adherent to antihypertensive medication $(62.2 \%)$ was greater than that previously published using the same test (the Morisky scale). ${ }^{17}$ In most previously published studies, adherence to pharmacological treatment was evaluated using different direct and indirect tests, and consequently, comparisons between studies are difficult.

It is of note that the prevalence of hypertensive patients with controlled hypertension in this study, $45.4 \%$, was higher than those reported in other studies performed in Argentina (7-43\%). ${ }^{15}$ However, since all patients included were treated with antihypertensive drugs, the comparison of the level of control of hypertension between different sample populations is not adequate.

As expected, individuals with controlled BP show a higher adherence rate $(69.3 \%$ vs $53.3 \% \mathrm{p}<0.001)$. Interestingly, the use of fixed-dose combination was associated with both higher rates of adherence and higher rates of BP control. Although, in theory, the use of more antihypertensive drugs could be related to lower adherence, in this study the number of drugs did not differ significantly between adherent vs. non-adherent group. Since multiple drug treatments are often required in hypertension control ${ }^{16}$ fixed-dose drug combination may be an adequate approach to the "more drugs vs. better adherence" dilemma.

Analyzing the variables related to adherence, neversmoking was protective factor. We can hypothesize that avoiding the initiation of tobacco use has not only a beneficial effect on the prevention of chronic diseases, but also an indirect effect on improving adherence. Indeed, the non-adherent group had more frequent previous history of cardiovascular events. This could represent reverse causality and highlight that improving adherence in adult patients is a very difficult task.

Regarding the reasons of non-adherence to antihypertensive drug treatment, Burnier et al. ${ }^{6}$ identified two different mechanisms: 1 -short persistence, i.e., when the patients ceased their engagement with the dosing 
regimen on their own initiative (an act that is inherently willful, not arising from forgetfulness). 2-lapses in implementation (or execution), which is a consequence of forgetfulness or negligence. Therefore, knowing and being able to differentiate between the two types of adherence (persistence or execution) would allow formulating specific strategies aimed to improve one of the main reasons why hypertension is not adequately controlled. ${ }^{16-22}$ In our study, the lack of adherence was mostly due to forgetfulness in taking medications or in the time of intake ( $\sim 40 \%$ to both). Thus, the use of reminders such as alarms, telemedicine, prescription of fixed combinations and less complex regimens could improve adherence in our population.

Our study had some limitations. First, our crosssectional design precluded the assessment of temporality; rather, we could only obtain associations. Second, adherence was assessed using only one questionnaire the Morisky scale (only) - which has not been validated to the Argentinean population. However, the instrument had been used in previous studies in our country. ${ }^{23}$ The use of a second scale to measure medication adherence would have improved the reliability of our findings. Third, predictors of non-adherence such as a poor patient-provider relationship and time of treatment were not evaluated in this study. Fourth, although this study was carried out in eight cities of different provinces, Argentina is a very large country and a study that covered a greater number of cities, would have greater representation. However, the prevalence of hypertension control was similar to that reported in a previous study conducted in Argentina. ${ }^{12}$ Finally, since hypertension control was determined based on BP office values, the possible white coat effect cannot be ruled out. Thus, despite these limitations, our study provides an estimation of non-adherence in an Argentinean cohort.

\section{Conclusions}

In conclusion, adherence rate to antihypertensive drug treatment was higher than the one reported in the literature, but still deficient. The main reason for non-adherence to pharmacological treatment was forgetfulness of medication intake. Therefore, differentiating the two types of adherence (persistence and execution) would allow formulating specific strategies aimed to improve the main reasons why hypertension is not adequately controlled. Finally, the lack of adherence was an important issue in patients with established cardiovascular disease.

\section{Author contributions}

Conception and design of the research: Sabio R, Diaz A. Acquisition of data: Parodi R. Analysis and interpretation of the data: Leiva CES. Statistical analysis: Leiva CES. Writing of the manuscript: Espeche WG, Salazar MR. Critical revision of the manuscript for intellectual content: Grimaldi D, Poppe S, Altube J. In old de conception: Salazar MR and Espeche WG.

\section{Potential Conflict of Interest}

No potential conflict of interest relevant to this article was reported.

\section{Sources of Funding}

There were no external funding sources for this study.

\section{Study Association}

This study is not associated with any thesis or dissertation work.

\section{Ethics approval and consent to participate}

This study was approved by the Ethics Committee of the Comitefyth under the protocol number EMA1. All the procedures in this study were in accordance with the 1975 Helsinki Declaration, updated in 2013. Informed consent was obtained from all participants included in the study. 


\section{References}

1. World Health Organization.WHO. A global brief on hypertension. Silent killer, global public health crisis. Geneva: World Health Organization; 2013.

2 Sabate E. Adherence to long term therapies. Evidence for action. Geneva: World Health Organization; 2003.

3. Law MR, Morris JK, Wald NJ. Use of blood pressure lowering drugs in the prevention of cardiovascular disease: meta-analysis of 147 randomised trials in the context of expectations from prospective epidemiological studies. BMJ. 2009 May 19;338:b1665.

4. ManciaG, Fagard R, Narkiewicz K, Redon J, Zanchetti A, Bohm M, et al. $2013 \mathrm{ESH} / \mathrm{ESC}$ Guidelines for the management of arterial hypertension: the Task Force for the management of arterial hypertension of the European Society of Hypertension (ESH) and of the European Society of Cardiology (ESC). J Hypertens. 2013;31:1281-1357.

5. van Veen WA. Treatment adherence in hypertension: problems and research. J R Coll Gen Pract Occas Pap. 1980 Jul;(12):22-5.

6. Burnier M, Wuerzner G, Struijker-Boudier H, Urquhart J. Measuring, analyzing, and managing drug adherence in resistant hypertension. Hypertension. 2013;62(2):218-25.

7. van der Laan DM, Elders PJM, Boons CCLM, Beckeringh JJ, Nijpels G, Hugtenburg JG. Factors associated with antihypertensive medication nonadherence: a systematic review. J Hum Hypertens. 2017;31(11):687-94

8. Agbor VN, Essouma M, Ntusi NAB, Nyaga UF, Bigna JJ, Noubiap JJ. Heart failure in sub-Saharan Africa: a contemporaneous systematic review and meta-analysis. Int J Cardiol. 2018 Apr 15;257:207-15.

9. Nyaga UF, Bigna JJ, Agbor VN, Essouma M, Ntusi NAB, Noubiap JJ. Data on the epidemiology of heart failure in Sub-Saharan Africa. Data Brief. 2018 Apr;17:1218-39.

10. Vrijens B, De Geest S, Hughes DA, Przemyslaw K, Demonceau J, Ruppar $\mathrm{T}$, et al. A new taxonomy for describing and defining adherence to medications. Br J Clin Pharmacol. 2012;73(5):691-705.

11. Naderi SH, Bestwick JP, Wald DS. Adherence to drugs that prevent cardiovascular disease: meta-analysis on 376, 162 patients. Am J Med. 2012;125(9):882-7.

12. Marin MJ, Fábregues G, Rodríguez PD, Díaz M, Paez O, Alfie J, et al National Registry of Hypertension. Awareness, Treatment and Control of Hypertension. The RENATA Study. Rev. Argent. Cardiol. 2012;80(2):121-8.
13. Corrao G, Parodi A, Nicotra F, Zambon A, Merlino L, Cesana G, et al. Better compliance to antihypertensive medications reduces cardiovascular risk. J Hypertens. 2011;29(3):610-8.

14. Morisky DE, Ang A, Krousel-Wood M, Ward HJ. Predictive validity of a medication adherence for hypertension control. J Hypertens. 2008;10(5):348-54

15. C Carbajal HA. Optimal blood pressure and high normal blood pressure in La Plata, Argentina. Can J Cardiol. 1994;10(7):749-52.

16. Carey RM, Muntner P, Bosworth HB, Whelton PK. Prevention and Control of Hypertension: JACC Health Promotion Series. J Am Coll Cardiol. 2018;72(11):1278-93

17. Hyre AD, Krousel-Wood MA, Muntner P, Kawasaki L, DeSalvo $\mathrm{KB}$. Prevalence and predictors of poor antihypertensive medication adherence in an urban health clinic setting. J Clin Hypertens. 2007:9(3):179-86

18. Hamdidouche I, Jullien V, Boutouyrie P, Billaud E, Azizi M, Lauren S. Routine urinary detection of antihypertensive drugs for systematic evaluation of adherence to treatment in hypertensive patients. J Hypertens. 2017;35(9):1891-8.

19. Calderón-Larrañaga A, Diaz E, Poblador-Plou B, Gimeno-Feliu LA, Abad-Díez JM, Prados-Torres A. Non-adherence to antihypertensive medication: the role of mental and physical comorbidity. Int J Cardiol. 2016 Mar 15;207:310-16.

20. Gentil L, Vasiliadis HM, Preville M, Bossé C, Berbiche D. Association between depressive and anxiety disorders and adherence to antihypertensive medication in community-living elderly adults. J Am Geriatr Soc. 2012;60(12):2297-301.

21. Holt E, Joyce C, Dornelles A, Morisky D, Webber LS, Muntner P, et al. Sex differences in barriers to antihypertensive medication adherence: findings from the cohort study of medication adherence among older adults. J Am Geriatr Soc. 2013;61(4):558-64.

22. Holt EW, Muntner P, Joyce CJ, Webber L, Krousel-Wood MA. Healthrelated quality of life and antihypertensive medication adherence among older adults. Age Ageing. 2010;39(4):481-7.

23. Ingaramo RA, Vita N, Bendersky M, Arnolt M, Bellindo C, Piscorz D, et al. Estudio Nacional Sobre Adherencia al Tratamiento (ENSAT).Rev Fed Arg Cardiol. 2005;34(1):104-11. 